\title{
Correctional Officers' Perceptions about the Safety and Control of Prohibited Items Entering into Prisons and Penitentiaries
}

\author{
Dittita Tititampruk ${ }^{*}$ and Tanet Ketsil ${ }^{\#}$
}

\author{
Faculty of Social Sciences and Humanities, Mahidol University, Thailand
}

\begin{abstract}
The smuggling of prohibited items is one of the significant problems faced by prisons worldwide. This research explores the smuggling of prohibited items into Thai prisons by examining the perceptions of 20 correctional officers, who are directly involved in the prevention and suppression of such issues, by using qualitative research techniques. The results reveal that although measures have been put in place to prevent the smuggling of prohibited items and avert any prison searches, there are still channels for smuggling items in medium and maximum-security prisons. Finally, how other strategies may be employed by correctional administrators to control their facilities and environments are discussed.
\end{abstract}

Keywords: Prohibited items in prisons, awareness of correctional officers, smuggling items into prisons, security measures, qualitative research.

\section{INTRODUCTION}

Smuggling of prohibited items or "contraband" is a problem in correctional facilities wherein contraband sales and distribution inside the prison increase the safety risk of officers and inmates. Although there is a known risk of an inmate to prison staff violence, the understanding regarding the perceptions of the safety of the prison guards who have to directly confiscate, reprimand and implement regulations when contraband enters a prison facility remains unclear.

The Department of Corrections (DoC) is an agency in Thailand that plays a crucial role in the control of judicial prisoners. It is a governmental organisation responsible for handling offenders using the prison system custodial sentence. The DoC has the authority and duty to treat offenders under court judgements or by orders of competent officials following the Correctional Act and other relevant laws that prescribe guidelines for the treatment of the prisoners in compliance with the laws, regulations, regulations, policies of the Ministry of Justice. The DoC is also expected to follow the best practices of and criminology and penology.

Thailand's correctional management system is challenged by both overcrowding and control of prisoners. Because of the rapid increase in the number of inmates, while the staffing rate remains the same, and because of limitations in various fields, the performance of duties under the mission of the DoC falls below the expected standard. One of the problems

*Address correspondence to this author at the Department of Social Sciences, Faculty of Social Sciences and Humanities, Mahidol University, Salaya, Phutthamonthon, Nakhon Pathom 73170 Thailand; Tel: +6681-926-6287; E-mail: dittita.tit@mahidol.ac.th; ${ }^{\#}$ E-mail co-author: tanet.ket@mahidol.ac.th caused by the imbalance between the number of prisoners and the prison officers is the smuggling of prohibited items into prisons. This issue is exacerbated by the changes in the profile of inmates. Previously, the majority of prisoners were persons who had committed crimes because of economic need, poverty, and lack of education. At present, however, many inmates exert influence within and outside prison, especially the major drug traffickers. These prisoners possess significant wealth and can smuggle prohibited items into prisons, such as mobile phones, drugs, and weapons. Although the DoC has always had search and prevention measures, it has proved impossible to catch the perpetrators because of their networks and finances. The smuggling of mobile phones into prison led to the problem of ordering drugs into the prison (or even outside), negatively impacting the image of the DoC.

Prison security was one of the areas that the DoC had to focus on because smuggling might not be limited to drugs but, as shown in one study, might include items that would undermine prison safety.

\section{Routine Activity: The Boundary Theory}

It is difficult to imagine an environment with more "motivated offenders" accustomed to routine activities than the prison environment. Prisoners have plenty of time for observing the activities of the guards and the characteristics of security routines. Therefore, it is not difficult for many of them to calculate the times and locations of "lack of guardianship" within the prison walls. Prisoners motivated to bring contraband into the prison may exploit the times and places when they can act unobserved from the guards, cameras, and other inmates and successfully manage to smuggle many 
contraband items. Nonetheless, as the security level increases in modern prisons, weaknesses in the defence against contraband are more difficult to identify and exploit.

\section{Contrabands Problem, Impact, and Safety Concerns of the Guards}

From several prior studies, it is evident that the motivation to get contraband items into prisons is associated with new crimes and with the desire to commit illegal activities without being monitored. The need to adopt effective security measures to all the levels of prison security is necessary for controlling such problems in all types of institutions.

Although most prison systems are designed to exert formal control over the inmate population, there are always some misconduct issues, such as sexual abuse, drug smuggling, and contraband, inside the prison. Currently, these problems appear to be increasing. The issue of smuggling prohibited items could be the most serious problem in prisons worldwide, such as the United States, Korea, and Singapore, including Thailand, because of the severe potential consequences from many contraband items. In particular, the most notable consequences include a loss of control over the inmates and threats to the safety of the inmates, prison officers, and facilities.

\section{Contraband Concealment Methods vs. Detection and Prevention Methods}

Prior studies and reports also state that smuggling contrabands into the prison have been accomplished not only by inmates but also by visitors and employees, who smuggle wireless phones and related devices into prisons (Vijayan \& Chethiyar, 2020; Buchanan, 2010; Binetti, 2008). In some cases, prison officers have accepted several hundred-dollar bribes per item, especially drugs, tobacco, and mobile phones, from inmates for facilitating and sneaking mobile phones into the prison (Burke \& Owen, 2010). In a country like Thailand, some inmates' family members, relatives, friends and other individuals pretending to be visitors have been employed by inmates to help with smuggling and concealing contrabands into the prison for large payments (Department of Corrections [DoC], 2016). Prevention methods must include measures that control visitors and prison employees, along with measures that control prisoners and contraband smuggling inside the institutions. Research regarding control of contrabands in U.S. prisons has shown that the scale of the problem is large and the serious consequences of failure to effectively prevent contraband from coming into prisons. However, there has been no clear discussion of control methods in the perception of prison guards and neither explanations of the effectiveness of specific control techniques.

It was, therefore, important to develop measures for prison security and the safety of correctional officers themselves. Research in this area will help expand the body of knowledge in academic and professional circles. However, there is a gap in the current literature between known safety risks and the smuggling of prohibited items within the prison system. There is no known literature where prison guards have been interviewed regarding their perceptions on their safety and issues of the smuggling of prohibited items.

Therefore, this research study explores the differences between medium and maximum-security systems to better understand how prohibited items are smuggled into the facility and how this affects the safety of the guards involved. Moreover, the research will fill that gap by examining perceptions of safety concerns regarding dealing directly with the smuggling of prohibited items. Finally, the results of this study will identify the security measures that are most effective in controlling contrabands in prison environments. This will allow prison administrators to increase their control on many forms of criminal conduct committed by prison inmates by concentrating the most effective security measures into prison security routines; the opportunities that inmates have to commit traditional fraud and extortion, gang activity, contraband smuggling, escape plans, riot plans, etc., will be limited as contraband items are taken out of the environment.

\section{RESEARCH METHODOLOGY}

This research applies a mixed-method methodology. Documentary research was used in both Thai and international contexts, employing content analysis through concepts, theories, and related literature, combined with the study and analysis of the sample interviews. The qualitative research method was utilised by interviewing 20 correctional officers from three prison locations in Thailand whose work involved the control of prisoners and/or officers who were directly involved in the control of prohibited items at all levels of the position. The institutions included were (a) Bang Kwang Central Prison, which is a maximum-security facility, (b) the Central Correctional Institution for Male Drug Addicts, which is a maximum- 
security facility, and (c) Bangkok Remand Prison, which is a medium-security facility.

Purposive sampling was used to select the interviewees, who were divided into two groups classified by position level and duty associated with contraband problems. The first group was the director of the custody division or wing chief, who made policy, issued directives, and controlled the operations. The second group comprised "warders," who are officers directly responsible for the prevention of prohibited items. However, the sample was limited to participants who had at least 1-2 years experience in performing duties related to the smuggling of prohibited items into prisons. This study was conducted between June and October 2020.

Although,20 respondents could be completely interviewed and it seems to be very small samples, however, their responses to the questions could be deeply informative and it is enough to analyse to interpret the interesting results on this sensitive issue. In addition, this research is a very sensitive and secure topic, so not many people would like to give information or the respondents is very hard-to-reach, however, the researcher utilized several interviewed techniques and using snowball sampling technique to reach the respondents and access their information.

\section{Conceptual Framework}

Based on the literature review, the researchers established a framework for examining the perceptions of correctional officers on the safety and control of prohibited items from prisons, as shown in Figure 1.

\section{Research Instrument}

The qualitative research instrument was a structured questionnaire for in-depth interviews divided into four sections based on the conceptual framework: (a) background and experience in performing duties related to the security and control of prohibited entry; (b) perceptions of correctional officers on the safety and control of prohibited items from entering prisons; (c) perceptions of correctional officers on measures and guidelines for the development of preventive and control measures related to the smuggling of prohibited items and (d) additional suggestions (if any).

This research obtained the Human Ethics Certification following the regulations set by the university, which has been accredited by the Office of the Human Research Commission, Faculty of Social Sciences and Humanities, Mahidol University, Credential No. 2020/154.2907. The in-depth interview questions of this research have been reviewed by a panel of judges to ensure this research was compliant with a research-based process and adhered to international standards.

\section{Data Analysis}

To ensure complete interview information, the investigator asked permission from the interviewee to tape the interview and take notes. Interview questions

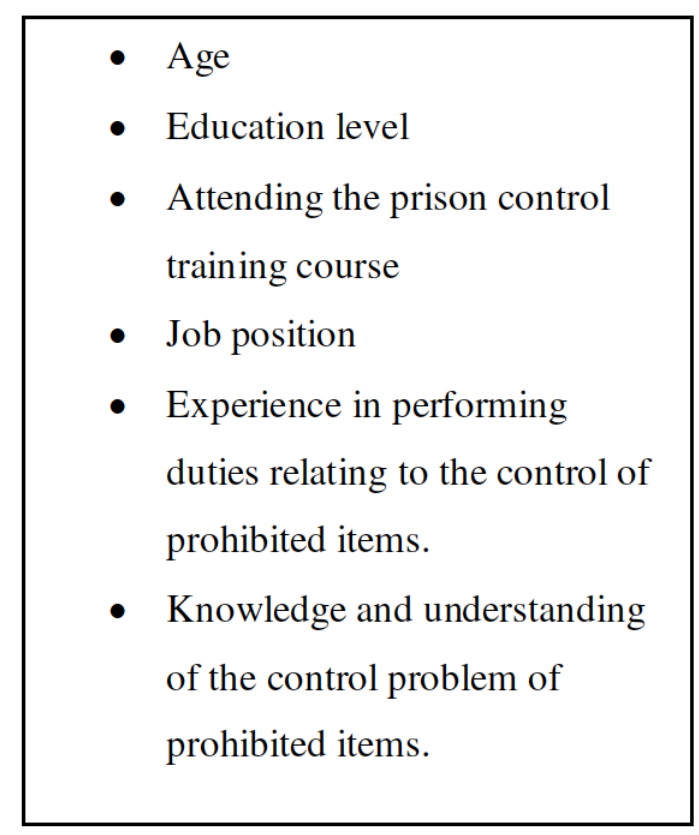

Figure 1: Conceptual framework.
Perceptions of correctional

personnel of the safety and

control of prohibited items

Perceptions of correctional

personnel on measures and

guidelines for the

development of measures to 
help answer research questions by providing complete and accurate insights into how correctional officers feel about the issue of prohibited items entering prisons. After completing data collection, the investigator analysed the data using the NVivo programme for analysis, with interviews and data analysis conducted through a qualitative analysis method. The conclusions drawn from the study were shown to the interviewees for a review and verification of their accuracy.

\section{RESULTS AND DISCUSSION}

Prohibited items or contraband in prisons refer to items that are prohibited inside the prisons, including drugs, drug paraphernalia, communications devices, weapons, tattoo equipment, weapons, gambling equipment, and tobacco or smoking equipment. Prisoners or prison officers are not allowed to possess such items while inside the prison facilities. It is a criminal offence to bring any form of contraband onto prison property. This section will present the findings, interpretation, and discussion based on the following research questions: (i) What are the correctional guards' perceptions regarding prohibited items being smuggled into their facility? (ii) What types of programmes or regulations are currently implemented in their facility for controlling contraband? (iii) What are the officers' perceptions regarding these programmes and their effectiveness for keeping their facilities safe? (iv) In facilities dealing with contraband issues, what are some effective measures or regulations that could be implemented to make them safer?

\section{Correctional Officers' Background and Experience in Performing Duties Related to the Security and Control of Prohibited Items}

There are little to no training courses in Thailand related to the control of prohibited items of correctional officers. The research results show that the chief officers, before being appointed to the control of prohibited items, never received any specific training in this area, such as the Warden's Guidelines, the Prison Commanders Program, policy on the prevention of general prohibited items, and workshops on prevention and suppression of prohibited items. This corresponded to the officers-level participants who spoke about their experiences with training before coming to work in the agency. It was found that, although most of the operating officers had already received training, such as drug-specific course training, special operations training, and organised departmental seminars, there was no specific course on the control of prohibited items or the control of illegal activities in prison. Most of the officers were appointed based on their past work experience, but some got their posts because of experience, raids, regulations, and laws.

However, if in the future, the DoC has policy to offer training courses or training techniques and control methods in the inspection of prohibited items, the prison wardens group commented that this is not necessary. The agency officers already have special experience and expertise in the control of prisoners, and their duties at prisons already have clear requirements. However, if the training was recommended, it should be a subject in the Warden and Commander curriculum, such as training in search techniques and interrogation.

The prison practitioners, in contrast to the chief group, felt that there should be more training on specific courses on prohibited items in the prison, such as mobile phones, drugs or weapons, and training on drug classification, smell, and appearance, through allowing prison officers or lecturers with real work experience to share their expertise on prohibited items, adapted to the culture of each prison. In addition, training courses on search and hiding techniques should also be offered, and new technologies to assist personnel should be made available. Specialised courses should be added for newly relocated officers who lack knowledge or expertise, and training should cover all areas, from the search of forbidden items, command, operation conducting disciplinary action, law enforcement, interrogation, and investigation.

\section{Type of Prohibited Items Smuggling into Prisons/Penitentiaries}

Among prohibited items smuggled into prisons, most officers in medium- and maximum-security facilities agreed that the most frequent were mobile phones and drugs. There were also prohibited weapons prisoners made from scrap metal, metal, welding wire, and vocational training metal; gambling equipment, such as playing cards made from soapboxes and dice made from flour and glue; sex toys; tattoo ink and cash. People who smuggled mobile phones into prisoners were visiting relatives, vendors, and prison officers. The tiny size of mobile phones lets prisoners hide these devices in their bodies, and prisoners have also been found with phones in their anus (DoC, 2009). 


\section{How Prohibited Items are Smuggled into the Prison and Accessed by Prisoners within Thai Medium- and Maximum-Security Prisons}

All correctional officers were asked to explain their perceptions and experience regarding how prohibited items get into the prison. Most prohibited items are smuggled into Thai prisons through gates and from over the wall. There are several main routes of entry that are similar for medium- and maximum-security prisons:

1. Entry by prison staff: Prison officers carry in items with other baggage when entering on duty, concealed by the body, clothes, shoes, food boxes/bags, or consignments in the prison. More than half of respondents indicated that there were many cases of uniformed staff bringing contraband into prisons in the past five years. Several correctional officers who brought prohibited items into facilities were fired and had been convicted for their criminal offence. However, two prison wardens from maximumsecurity prisons and four practitioners believed that only a minimal percentage of their staff members could either be actively bringing in or allowing prohibited items into their establishments given the harsh punishment and impacts [WD002, WD007; P0012, P0015, P0017, PO020]. ${ }^{1}$

2. Entry by prisoners: Prisoners hide items in their body, along the belt, in the mouth or the rectum, and inside the prison, such as on the ceiling, in the room, on the wall, or in the toilet. Some officers stated that most prisoners might have smuggled prohibited items when appearing in courts, appearing in hospitals, or getting back from public work. Sixteen respondents stated that prisoners usually bring prohibited items back into prisons via family members, lawyers, outsiders, court security staff, or medical staff. Two respondents of 16 described their experience regarding the detection of prisoners after getting back from the outside. Some escort services were hired by the family or friends of the prisoners to smuggle drug-filled cigarettes into the prison and to the prisoners without being noticed by others [WD001, WD003]. Normally,

${ }^{1}$ Note that anonymous codes have been used for the interviewees in the present research for the sake of confidentiality. "PO" refers to prison officers, while "WD" refers to the warders. legal or security staffs sometimes acquire special privileges and are exempt from searches or detection, which makes it easy to conceal contraband.

3. Entry via social visit: Although social visits by family members, relatives, and other visitors are one of the significant welfares provided by Thai DoC to prisoners, which also helps prisoners release some stress, it could be one popular route for handing contraband into prisons. Relatives and other visitors hide items along with belts, dresses, souvenirs, books, and food packages. Twelve officers indicated that the policy of allowing outside foods or necessary items for prisoners via social visit in the three years before the study is one significant problem that enables the prohibited items from flowing into prisons, especially drugs, mobile SIM cards or even weapons. Drugs are transformed into food ingredients mixing in several menus, such as chicken soup, hamburgers, pork balls, etc.

Moreover, items were sometimes thrown over the prison walls by the prisoners' family members, relatives or drug delivery men. More than half of respondents indicated that they could observe and detect some prohibited items falling into the base floors, which are close to the prison walls. Some of the respondents said that it was very weird and hard to detect when contraband was hidden in weird packages, such as dead cats or birds. Drugs and mobile SIM cards were the two most hidden items and were thrown over the prison walls [WD004, WD007; P0009, P0010, PO012, PO019].

4. Entry via vehicle: Items are hidden through delivery vehicles, junk cars, public cars, or vehicles that deliver food, in professional training work, aid shops that bring goods into the store. Another particularly important avenue was the kitchen car, which was difficult to detect because of the raw meat, pork, chicken, beef, and cooking ingredients as well as the relatively large quantity of items to be checked [WD001, P0013, PO018].

5. Entry via other stuff: Some contraband items are brought into prisons hidden in postal parcels, souvenirs, photo albums, and picture frames sent to prisoners by relatives or third parties. The packaging needs to be modified making it 
difficult to detect and search. For example, a thick book is modified by making a hole to hide some drugs, cigarettes, illegal pills, or mobile SIM cards [WD005, PO014, PO016, PO020]. Some photo albums or picture frames are decorated with items that prisoners could use, such as tattoo tools, which are prohibited inside prisons [WD007, P0010, P0017].

\section{The Detection Methods to Search and Find Prohibited Items when Entering Prisons/ Penitentiaries}

Most correctional officers explain not only the routes of entry but also the current detection methods that most prisons and correctional institutions usually put into practice. Generally, there are three common detection methods that medium- and maximumsecurity prisons usually implement.

Method 1: Search and invasion search for special cases. According to a prison policy, a regular search schedule should be set up at least once a month for medium prisons, probably twice a month in maximumsecurity facilities. Invasion search was implemented when the superintendent or warden received classified information and ordered a clandestine invasion search operation. The search operation should be undertaken suddenly and confidentially without prisoners noticing. Several prohibited items were discovered after receiving orders from the prison supervisor to search a specific area [WD003, P0011, PO017, PO019].

Method 2: Accidental discovery. Some drugs, mobile phones, SIM cards, or other hidden stuff were found accidentally. They usually are discovered during acts such as mowing the grass, dredging a canal along the wall, and finding a package, such as netbooks, methamphetamine, heroin, or marijuana. Of 20 officers, 13 indicated that $60 \%$ of contraband items were discovered accidentally through routine activities inside prisons [WD001, WD002, P0012].

One officer-related an interesting story regarding illegal drugs hidden in a dead cat, which was thrown over the walls. Initially, no one could notice any abnormality regarding the dead animal until a fifth dead cat was found in the same area and around the same time as the other dead cats. Wardens and officers agreed to check the abdominal section and looked into the dead cat's stomach and found half a kilogram of heroin [PO015, PO0014].

Method 3: Getting information from prisoners or other sources. This method required cooperation with some good officers or prisoners. These people act as a spy to get contraband smuggling information and report it to prison wardens or superintendents. However, trustworthy information is not simply received from detectives inside but prison wardens and superintendents also get notified from other network agencies, such as the police, narcotic control units, or even international parties. Operation plans for search and detection are implemented after reliable information was reported. [WD001, WD005, P0015].

\section{Correctional Officers' Perception Regarding the Safety Concerns}

One significant objective of this study is to examine the perceptions of correctional officers regarding the safety of themselves, their families, and those around them as well as safety concerns when a sample correctional officer was required to prevent the smuggling of prohibited items. The interview results represent the following information:

\section{Problems and Obstacles Related to the Management and Control of Smuggling of Prohibited Items into Prisons/Penitentiaries}

Problems in prison management/problems from officers:

1. There was a high prisoner-to-officer ratio, making it more difficult to supervise and control prisoners in a crowded place.

2. The great number of smuggled items made detection harder.

3. There was inadequate detection and supervision technology. Requirements included a surveillance camera, a scanner or X-ray machine, and a drug detector. Inadequate maintenance budget was also a problem.

4. Policies submitted from the centre were counterproductive to operations.

5. There were delays in searches due to excessive inventory and requiring detailed inspection, which increased the risk of prohibited items entering the prison.

6. Officers lack the skills, knowledge, and expertise in controlling prohibited items. Officers are not sufficiently committed to preventing smuggling.

7. There is poor control of prisoners. Officers neglected to perform their duties. 
8. There were limitations in the search. Legal and human rights issues, such as raids requiring undressing, which may be accompanied by relatives of prisoners, were impractical. Rectal examination or removal could lead to complaints about violating human rights The officers were unable to do thorough searches.

9. Walls in urban areas made it easy to throw prohibited items into the prisons.

10. Disciplinary sanctions were sometimes not severe enough and delayed, for both prisoners and officers. The punishment was unclear, so there was no fear of wrongdoing.

Problems from prisoners:

1. Some prisoners came from financially influential groups, which often bribed or threatened officials to import prohibited items.

2. Prisoners were skilled in smuggling prohibited items.

3. There was the networking of prisoners, sometimes by the major drug traffickers. When in different regions, communication is difficult, but in the same prison, buyers and sellers can make their arrangements more easily.

Impacts on Safety when Managing and Controlling the Illegal Smuggling of Prohibited Items into Prisoners/Penitentiaries

\section{Effects of Prohibited Items on Prison Safety and Administration}

The bad image of prison administration regarding the uncontrolled contraband smuggling impacts the prison staff performance. Lack of trust by the public has created unprofessional officers and a lack of credibility in prison operations. There is a conflict between the officers. If there are prohibited items, in some cases, officers are involved in this criminal offence.

\section{The Safety Implications for Prison Officers}

Officers suspected of smuggling were investigated and prosecuted according to the law, but when there was an issue of disciplinary action, public perception was that all officials were involved. The agency was not transparent, causing workers with good intentions to become frustrated. Stress and anxiety affected prison officers' performance. Officers who performed well in their duties would also lose morale. In addition, workers in defence and suppression are often intimidated, creating concerns about their safety, lives and property. Prisoners with money, power and contacts pose a high risk to officers. Prisoners have a process to divide the officers by causing misunderstanding and conflict between them.

Impact on the Safety of other Prisoners

Prohibited drugs led to arguments and even violence. When this happened, prisoners who were in the room, or were part of the group, would be accused of involvement. Thus, prisoners who have not directly involved suffered the consequences. Prisons, therefore, needed to adopt more stringent and tighter regulations. The small number of offences impact the majority, such as having their TV viewing or packages banned. If any prohibited items were found in food, they would be ordered to refrain from food. In addition, if there were a large number of prohibited items being smuggled, the network expands. Some groups of smugglers had significant influence and provided incentives for other prisoners to get involved in smuggling or threatened other prisoners so that they would not inform the authorities. Prisoners who were working with officers were informants, or were involved in getting prohibited items were intimidated by other prisoners.

These operational problems and impacts were also found in Panchaphakdi (2020). The data obtained from the interviews with the sample were categorised and analysed for the office of the Minburi Special Prison. Issues that affected the safety of correctional officers, their families, and those around them included the following: (a) the need to work very closely with prisoners; (b) insufficient equipment and tools for the number of officers at risk of physical harm when brawls broke out among prisoners; (c) health risks due to congestion among prisoners, including the spread of communicable diseases among prisoners; (d) lack of opportunity to participate in various activities with family members, resulting in unstable family relationships; (e) advancement in duties and compensation are relatively minor or non-existent and (f) lack of manpower that resulted in prison workers functioning under stressful conditions with prolonged lack of rest.

\section{The Effective Measures for Prison Security and Controlling of Prohibited Items}

The results of the study on the development of effective security measures in prison security and the control of prohibited items from entering into prisons to eliminate and mitigate the problems that may arise 
from smuggling. Through the study, the researcher has found a way to develop the most effective security measures for the control of prohibited items.

\section{Measures or Policies for the Prevention and Control of Smuggling of Prohibited Items into Prison Include the following}

Searches of Personnel Entering and Exiting through the use of X-Ray and Metal Detectors and Ground Scanners

Searching buildings, sites, vehicles, and cells; wall guards regularly inspecting, checking the walls, and conducting thorough searches. Authorities will regularly observe the behaviour of visitors and intensify search measures for detained and returning prisoners.

Raids, Arrests, and Searches were Carried out to Find Prohibited Items

Increasing the frequency of regular searching schedule as well as increasing the efficiency of the search by improving the technique of detecting weak spots and increasing the intensity of thorough searches. Meanwhile, additional netting as the barrier net walls should be considered to prevent the throwing of prohibited items via prison walls.

\section{Prevention and Suppression Measures}

Drug prevention measures take the same approach as other searches but focus on establishing a network of prisoners to acquire information, document such intelligence, and analyse information with related agencies in drug suppression, integration, with external agencies involved in prevention and drug suppression. A carpeted raid was a site-wide search that covers the most common areas, cell blocks, common areas within the prison, and the target prisoners. Carpet inspection was time-consuming but very effective.

\section{News Search Measures}

Particular care should be exercised with prisoners returning from court because drugs could be smuggled. Officers should use informants and closely observe the behaviour of prisoners going to court. Upon exiting the court, the prisoners should be brought into the prison, where special precautions have to be taken, and a secret search should be conducted to report intelligence on the behaviour of these prisoners

Measures to Instil Ethics and Organising Activities, Measures to Instil Ethics, Create Values and Instil Consciousness in Officers

In addition, there should be training to educate the prisoners about the dangers of prohibited items, as well as the punishment if arrested because of these prohibited items. There were penalties for offenders such as detention and transfer to another prison. In addition, professional work, education and good hygiene should be developed for prisoners according to their rights, and the practice of working against offenders in the community should be widely adopted since this will reduce the overcrowding in the prison. This was consistent with the research report of Dharathup (2019), who found that prisoners' behaviour improved by making them conscious of good, evil, fear of sin, mental development, meditation training, religious activities, vocational skills training, education at different levels, rehabilitation in health promotion and fostering awareness and social responsibility to be able to live in a society with a career to support themselves, be self-reliant and have human dignity. Simultaneously, prisoners were an economically beneficial labour force, were able to reduce the prison budget burden by providing professional training that meets both the needs of prisoners and the labour market. They were able to connect with communities, became socially accepted, increased employment opportunities for former prisoners, reduced recidivism rates and, by "returning good people to society," fulfilled the mandate of correctional policy.

\section{Development Guidelines for Solving the Smuggling and Control of Prohibited Items into Prisons in a Concrete and Effective Way}

\section{Physical Characteristics of the Prison}

Informants suggest that prisons should do away with their walls because prisons were in urban areas and walls that were stuck in the city, making it easy to throw prohibited items. If a wall was retained, a solid defence system should be provided, such as an additional net barrier measure around the three-layer fence net, preventing prohibited items from being thrown away from the boundary of the wall, with a thorough front-entry search. In addition, the prison should be located far from the community, there should be an area between 5 and $10 \mathrm{~km}$ before the boat wall, and there must be no houses nearby to prevent it. There should be three to four layers of fences. Dog patrols and electrified fences provide additional protection.

\section{Intensive Legal/Disciplinary and Operational Measures}

The informant suggested that legal measures should be improved and more penalties should be imposed. Any prisoner committing an offence should be punished severely, such as eliminating some 
privileges, rejecting the request of social visit with families, or even getting more sentences from such smuggling offences to instil the fear of committing a crime. In the event of offences against officials, prosecution or disciplinary action against officials must be severe and immediate to avoid the prisoner getting help or pleas. Law enforcement should be fair. Supervisors should always monitor the performance of their subordinates. Responsibilities should be rotated to mitigate the risk of offending an officer and assign a division supervisor, supervisor, or division director to observe the behaviour of the offender and report the conduct.

\section{Search Measures}

Informants suggest that a more thorough search should be done, not just random checks, with no exceptions. The measures for assault detection should be increased. There should be coordination with related agencies. Police dogs should be brought to search for prohibited items. There should be an internal network of informants. A news source that delivers internal news with a security system for the newscaster should be created. Tititampruk (2020) suggested that prisons also face an ineffective prison-search problem. To improve search effectiveness, prisons should follow the five steps of correctional policy (Department of Correction, 2016a, and 2016b) to guide the organisation of prisons. Moreover, the international standardised search system should be implemented seriously, and prison executives should establish a plan or a search pattern according to the international standard and set it to be the same standard throughout the region.

The Introduction of Technology Systems, Equipment, or Tools in the Prison

The informant recommends that the operational support equipment such as scanners or X-rays for prohibited items should be allocated with an adequate number of officers. High-efficiency technology in detection, such as technology to cut phone signals, listening devices, surveillance cameras, body scans, drug detectors, and rectal examination chairs, should be brought to every prison. In addition, all search equipment should be maintained to be readily available for use. This was consistent with the study by Wongananchai (2013), who recommended that the prison should be equipped with CCTV cameras in every area such as cells, visit rooms, attorney meeting rooms, and the entrance and exit. This should be smart technology that did not require officers to watch but sounded alarms if something went wrong. Various tools were used, including installation of prison security systems or accessories to prevent escape, monitor behaviour and prevent illegal entry into prisons with Modifying the System during Operation via Configuration in RUN or "MIXCiR" machines, walkthrough metal detector, interceptor, jammer, body scanner, X-ray or CCTV. In addition, prisoners must have a barcode data band or an electronic radio frequency identification tracking system with the CCTV system connected to the war room in the DoC. There should be cameras and handcuffs for all prisoners. Also required were spotlights, communication tools, and self-defence equipment such as batons, Prithai spray, electric shock, whistles, and flashlights.

\section{Personnel/Personnel Rate}

Interviewees suggested that more courses should be added to training techniques for handling prohibited items and observation techniques for the use of new technologies to develop officers with increased intelligence and knowledge. A forum must be organised to exchange knowledge between officers who practice prohibited items, as some prisoners are now highly skilled in smuggling prohibited items. Officers must always increase their knowledge and experience. Selected officers must be knowledgeable, must be skilled, must be experienced, must be honest, must be fair, must not exploit prisoners, should have experience and knowledge in controlling prisoners and should not neglect their duties.

In addition, the agency should provide adequate incentives to the officers. through performance evaluation, promotion, salary increase, or convenient positions. Awards and commendations were given to increase officers' morale. Winsarivej (2020) suggested that a person should know the criteria for performance evaluation for promotion and should be encouraged to develop knowledge and competence of personnel and should consider salary adjustments by government officials.

In terms of manpower ratios, more personnel should be allocated for the control of prisoners. Search rates should be increased owing to excessive inventory and thorough inspections required to reduce the likelihood of prohibited items entering prisons. Chanprasert (2012, p. 157) recommended an effective officerprisoner ratio. There should be a continuous relocation of personnel, and the personnel was encouraged to receive additional training and acquire knowledge in various fields. 
Correctional schools or correctional institutions should be established in the form of educational institutions, as well as police officers' schools and military schools. The curriculum and the morals, ethics and values of the organisation should be created. Ratanacharoen and Nuntiyakul (2015) noted that establishing the professionalism of correctional officers would require a three-year plan. Continue to improve, correct and develop the existing institutions of correctional service by establishing a curriculum structure and a long-term plan, which was to build a correctional school, just like a military or police cadet academy, including the preparation of correctional professional standards, the job description of each position, the setting of the manpower framed separately from the Civil Service and the establishment of a Correctional Commission of the correctional service to supervise the administration like other independent organisations. A Correctional Commission of the correctional service will benefit students educated from correctional schools. Once they have passed the curriculum, they can be placed in government service if they have passed the entrance exam and assessment criteria.

\section{Dress Code}

The interviewees suggested that prison wear should be designed to be easily searched because the X-ray machine cannot detect drugs. A dress code should be drawn up, and attire should be specific to the prison; prisoners should not have excessive clothing.

\section{Boundaries for Surveillance}

Interviewees suggest that, when a prisoner returns from the court or from outside, that prisoner should be put under surveillance. Upon entering the surveillance area, prisoners should be required to bathe, followed by a thorough physical examination with officers and tools such as a body scanner, and given laxatives to prevent illegal ingestion for at least 3 days. Toilets in the surveillance area must be equipped with filter systems to catch objects.

\section{Welfare Store}

One interviewee suggested that there should be a mediator who was a correctional officer or a supervisor from a special, centralised unit. It could be operated in the form of a company or a single unit undertaken by the DoC and should have the sole authority to deliver food or any necessary items to the prison, thus reducing the interference of middlemen. In addition, when the prison deals with any shop, caution should be exercised with the stockroom, which should not be accessed by the shopkeeper. Locks must be secured manually and keys exchanged with the prison officers.

\section{Visiting Relatives/Meeting Lawyers}

Interviewees suggest that physical visits by relatives should cease and video conferencing be used instead. Guards should closely monitor prisoners' behaviour, especially when dealing with outsiders or in prisons.

\section{Integrating Cooperation with Relevant Agencies}

The DoC should enter into an agreement with the police, prosecutors, and courts on evasion of prison, using alternative methods instead of imprisonment to reduce the number of prisoners. In addition, learningexchange meetings should be held at least once a year with officials and relevant agencies to exchange experiences and recognise the problems and obstacles arising within the prison.

\section{Prisoners' Classification}

Senior agencies or supervisors should have the policy to classify prisoners. Currently, prisoners were co-located, which required an appropriate screening system. Prisons should have a system for prisoner classification and for screening prisoners that have separate methods for storing drug and mobile phone data and must have a systematic data linkage system. Chanprasert (2012, p. 158) recommended that prison/penitentiary administrators should continue to pay attention to the relocation of prisoners to reduce the burden of control officers, along with the systematic segregation of prisoners to facilitate the correction and development of the behaviour of prisoners, so they can become good citizens to live happily in society.

\section{Process for Identifying Prisoners in Specific Groups} and Professional Classification

Currently, although prisons were categorised as repeat prisoners or multiple convicts, their respective types of offences and prisons cannot be distinguished because the classification does not apply to the type of institution. Key interviewees proposed a method for handling prohibited items by identifying the people who were causing problems for the DoC-i.e., the problematic prisoners. These must be identified and screened and removed from the group. When this group of prisoners can be screened, the prisoners can be classified.

Niyomphon (2018) argued that Thailand's prisoner classification should follow Japanese principles. 
Japan's classification of prisoners is at the heart of remediation for prison offenders. The concept and philosophy of prisons is rooted in the progressive remedial system. The classification system separated males and females, emphasising scientific classification, individual practice and social reintegration. There were four types of prisons: the prisons where the courts-imposed conditions to work; the prisons for the hard prisoners with no conditions to work; the places of detention and the detention facilities based on medical examination, psychology, sociology, and other techniques. Treatment programmes were organised according to the needs of prisoners for each category of psychological testing and personality testing, where are widely used in prisons.

It can be seen from the study that Japan's process of seeking information for use in detecting prisoners was based on medicine, psychology, sociology, and professional knowledge, which initially sought information. This will be used to characterise the new prisoners with follow-up to assess the progress of prisoners.

\section{SUMMARY}

There were two main methods for smuggling prohibited items through prisons: (a) brought into the prison gates by officers, outsiders, prisoners, and vehicles, and (b) thrown over a prison wall or with a glider. However, although the prisons had clear regulations on the handling of prohibited items, there were still many problems and obstacles in the workforce that vary, making it difficult for officers to perform their duties. Issues include manpower rates, prison congestion, lack of search tools and equipment, inadequate budget and inadequate technology, prisoners with financial influence, networks of prisoners, lack of skills and knowledge, lack of expertise in the control of prohibited items, and inadequate disciplinary sanctions in which the smuggling of prohibited items affects three areas: (a) Prison safety and administration make the prison difficult to control. This poor public image diminishes the credibility of officers in prison operations. (b) There is an impact on the safety of prison officers, including stress and anxiety in the performance of prison officers' work. Prisoners with financial resources and high-level contacts posed a high risk to officers. (c) Prohibited drugs led to arguments and even violence. When this happened, prisoners who were in the room or part of the group would be accused of involvement. Thus, prisoners who have not directly involved suffered the consequences. Prisons, therefore, needed to adopt more stringent and tighter regulations. The small number of offences impact the majority, such as having their TV viewing or packages banned. If any prohibited items were found in food, they would be ordered to refrain from food. In addition, if there were a large number of prohibited items being smuggled, the network expands. Some groups of smugglers had significant influence and provided incentives for other prisoners to get involved in smuggling or threatened other prisoners so that they would not inform the authorities. Prisoners who worked with officers were informants, or were involved in getting prohibited items were intimidated by other prisoners.

However, in medium- and maximum-security prisons, there were measures to prevent the smuggling of prohibited items, such as search, interception, and suppression measures, as well as preventive measures such as raids, informants, and ethical teaching. However, the consensus was that the measures were likely to be inadequate because of several factors. This was shown by the fact that prohibited items were still smuggled into most prisons. Agencies should consider measures to improve efficiency and prevent smuggling. For example, legal measures should be improved and heavier penalties should be imposed on any prisoners committing an offence. In the event of offences, the prosecution or disciplinary action against officials must be severe and immediate. The penalties of civil servants for offences should be investigated more carefully, without any exceptions. The measures for assault detection should be increased. There should be coordination for cooperation from related agencies. Police dogs should be brought to search for prohibited items. A network of prisoner informants should be created. In addition, there should be a security system for the informants, and technology systems, equipment, and tools should be introduced in the prison. The interviewee recommends that the operational support equipment such as scanners or X-rays for prohibited items should be allocated to suit the user's needs. The equipment must be sufficient for the number of officers.

\section{RESEARCH SUGGESTIONS}

1. Further research should cover the regional level, making the findings more useful for correctional work.

2. There should be in-depth investigations on measures to enhance the system of smuggling prohibited items into prisons, especially between low- and high-security prisons. 
3. Guidelines for establishing a prison with supermaximum security, a technology that will be used to support and control prisoners in large drug cases, should be studied.

\section{ACKNOWLEDGEMENTS}

The authors would like to thank the reviewers for their constructive feedback. In addition, the authors would like to thank Enago for the English language review.

\section{DATA AVAILABILITY}

The data that support the findings of this study are available from the corresponding author, DT, upon reasonable request.

\section{DECLARATION OF INTEREST STATEMENT}

No potential competing interest was reported by the authors.

\section{REFERENCES}

Binetti, R. (2008). Cell phones go to the dogs: Maryland uses phonefinding K-9s to step up security efforts. Corrections Today Magazine, 70, 58-61.

Buchanan, K. (2010). Our prisons, ourselves: Race, gender and the rule of law. Yale Law and Policy Review, 29, 1-65. https://doi.org/10.2139/ssrn.1687402

Burke T., \& Owen, S. (2010). Cell phone as prison contraband. FBI Law Enforcement Bulletin. http://www.fbi.gov/statsservices/publication/law-enforcement-bulletin/july-2010/cellphones-as-prison-contraband/

Chanprasert, S. (2012). Performance of the Central Women Correctional Institution in accordance with the main missions of the Department of Corrections [Master's thesis, Ramkhamhaeng University]. MPA Online, Ramkhamhaeng University (pp. 157-158). http://www3.ru.ac.th/mpaabstract/index.php/abstractData/view/ndex/252
Department of Corrections Bureau of Correctional Ology. (2009). Correctional news 360 degrees. Correctional Journal for the Advancement and Knowledge in Corrections, 3.

Department of Corrections, Planning Division. (2016a). Policy 5 steps for correctional change. http://wwwcorrect.go.th/popmaha/ image/5kawyang.pdf

Department of Corrections, Planning Division. (2016b). Correctional practice policy for the year 2016 (4th quarter). (The most urgent letter of the Department of Corrections. No. 0712.1 / 20572, dated 11 July).

Department of Corrections. (2016). Action plan of the Department of Corrections 2016-2019. Penology Division.

Department of Corrections. (2017). Annual report of state operations to the public fiscal year 2017. Vision Preserve.

Dharathup, N. (2019). The prison reform through process of rehabilitation for returning prisoners to society: A case study of Nangrong District Prison, Buririam Province. Veridian EJournal Silpakorn University, 12(5).

Niyomphon, K. (2018). Roles of correctional officers in enforcing prison sentences. Wittayani [Unpublished master's thesis]. Dhurakij Pundit University.

Panchaphakdi, C. (2020). Development of quality of life performance of correctional servants Minburi Special Prison Bangkok: Articles compiled from independent study [Unpublished master's thesis]. Ramkhamhaeng University. http://www.islocal.ru.ac.th/images/ispdf/is60/charoen.pdf

Ratanacharoen, N., \& Nuntiyakul P. (2015). The development of correctional officers for professionalism. EAU Heritage Journal Social Science and Humanities, 5(2), 37-47.

Tititampruk, D. (2020). A study of obstacles and measures to increasing the effectiveness of conducting inmate search according to international standard in Thai prisons. Journal of MCU Nakhondhat, 7(9), 375-393. https://so03.tcithaijo.org/index.php/JMND/article/view/246750

Vijayan, K., \& Chethiyar, S. D. M. (2020). Explorative study on the phenomenon of contraband cigarettes in Northern Malaysia. PEOPLE: International Journal of Social Sciences, 6(3), 917. https://doi.org/10.20319/pijss.2020.63.0917

Winsarivej, M. (2020). Personnel development of Thonburi special prison officers: A case study of morale enhancement [Unpublished master's thesis]. Rajamangala University of Technology Rattanakosin.

Wongananchai, S. (2013). Prevention and suppression of narcotics in prisons by enhancing the efficiency of control. Administrative Program for Senior Executives on Justice Administration, Class 17, College of Justice, Office of Justice.

Received on 12-05-2021

Accepted on 01-07-2021

Published on 09-07-2021

\section{https://doi.org/10.6000/1929-4409.2021.10.137}

(C) 2021 Tititampruk and Ketsil; Licensee Lifescience Global.

This is an open access article licensed under the terms of the Creative Commons Attribution Non-Commercial License (http://creativecommons.org/licenses/by-nc/3.0/) which permits unrestricted, non-commercial use, distribution and reproduction in any medium, provided the work is properly cited. 